Int. J. Morphol.,

31(1):254-263, 2013.

\title{
Infecciones de Transmisión Sexual en Semen. El Hombre como Vector de Transmisión
}

\author{
Sexual Transmission Infections in Semen. Men as Vector Transmission
}

Tamara Viscarra A*; Priscilla Brebi M.,"**; Alejandra Andana V.,"** \& Raúl Sánchez G.."

VISCARRA, A. T.; BREBI, M. P.; ANDANA, V. A. \& SÁNCHEZ, G. R. Infecciones de transmisión sexual en semen. El hombre como vector de transmisión. Int. J. Morphol., 31(1):254-263, 2013.

RESUMEN: En los últimos años el estudio de las infecciones de transmisión sexual ha cobrado gran importancia debido principalmente al incremento de estas en parejas heterosexuales y hombres que tienen sexo con hombres. En mujeres existe mucha información de epidemiología y patogénesis de estas infecciones, sin embargo, en hombres la información es muy escasa debido a que la mayoría no presenta sintomatología. En los últimos años se ha evidenciado un creciente interés en el estudio del semen como vía de transmisión, debido principalmente a la afinidad de algunos patógenos con los espermatozoides. Dentro de los principales microorganismos infectantes en semen se encuentran Chlamydia trachomatis, Neisseria gonorrhoeae, Mollicutes, Virus de la Inmunodeficiencia Humana tipos 1 y 2, Virus Herpes Simplex 1 y 2, Virus Papiloma Humano, Virus de la Hepatitis B y C, Citomegalovirus, Virus Epstein-Barr y Trichomonas vaginalis.

PALABRAS CLAVE: Infecciones de transmisión sexual; Semen; Virus; Bacterias; Protozoos.

\section{INTRODUCCIÓN}

En los últimos años se han incrementado los casos de enfermedades de transmisión sexual, debido principalmente al aumento en el número de compañeros sexuales en parejas heterosexuales y de hombres que tienen sexo con hombres (HSH), lo que hace aún más factible y rápida su propagación (Apers et al., 2012). Los principales riesgos asociados son daños irreparables en los hijos de madres infectadas durante la gestación o el nacimiento, entre éstos, ceguera, deformidades óseas, retraso mental e inclusive la muerte. Además, en las mujeres pueden causar enfermedad inflamatoria pélvica, infertilidad, embarazos ectópicos potencialmente mortales y cáncer en el aparato reproductor (Gupta \& Bowman, 2012). En hombres la infección está asociada a tumores de piel, región perianal, tonsila, orofaringe, laringe, esófago, próstata y uretra (Giuliano et al., 2008).

La principal forma de transmisión de estos microorganismos son las relaciones sexuales sin protección, ya sea por vía vaginal, oral o anal. El semen es susceptible de ser infectado por varios microorganismos, como bacterias, virus y protozoos, los cuales encuentran en el plasma seminal las condiciones óptimas para su supervivencia (Shim, 2011). El semen contiene una heterogeneidad de componentes: A) fracción celular: células espermáticas, leucocitos y células epiteliales, y B) fracción plasmática (Dejucq-Rainsford \& Jegou, 2001). Los espermatozoides pueden infectarse en el epidídimo, conducto deferente o uretra. Los microorganismos pueden estar presentes en el semen y asociarse con espermatozoides y/o otras células presentes en el líquido seminal como leucocitos, células epiteliales, glóbulos rojos, etc., especialmente cuando existe algún tipo de inflamación o trauma de las glándulas sexuales accesorias (próstata, vesícula seminal, o glándula bulbouretral) (Dejucq-Rainsford \& Jegou, 2004).

En la presente revisión se describirán los mecanismos de infección que tienen Bacterias (Chlamydia trachomatis, Mollicutes, Treponema pallidum, Escherichia

\footnotetext{
* Laboratorio de Virus Oncológicos en Reproducción, BIOREN-CEGIN, Universidad de La Frontera, Temuco, Chile.

*:Laboratorio de Patología Molecular, Departamento Anatomía Patológica, Facultad de Medicina, BIOREN-CEGIN, Universidad de La Frontera, Temuco, Chile.

Este trabajo fue financiado en parte por Proyecto FONDECYT postdoctorado 3120141, Proyecto Creación del centro de excelencia en estudios genéticos e inmunológicos (CEGIN) 09CN14-5960 y Núcleo de Desarrollo Científico Tecnológico en Biorecursos (BIOREN).
} 
coli), Virus (Virus Inmunodeficiencia Humana (HIV), Virus Papiloma Humano (HPV), Virus Herpes Simplex (HSV), Citomegalovirus (CMV), Virus Epstein-Barr (EBV), Virus de la hepatitis B y C) y protozoos (Trichomonas vaginalis) en semen, destacando sus características e importancia clínica.

\section{BACTERIAS}

Chlamydia trachomatis. Es una bacteria intracelular obligada que afecta tanto a hombres como mujeres. Es considerada uno de los patógenos de transmisión sexual más prevalentes en el mundo debido a que la mayoría de las infecciones son asintomáticas ( 75 a $85 \%$ en mujeres y de 50 a $90 \%$ en hombres), por lo que un gran porcentaje de personas pueden estar infectados sin saberlo (Pellati et al., 2008). C. trachomatis posee un ciclo de crecimiento de dos fases, la primera cuando se encuentra como cuerpo elemental infectivo (CE) y la segunda, como cuerpo reticulado no infectivo (CR). Al ocurrir la inclusión la clamidia se desplaza hacia el aparato de golghi mediante un mecanismo dependiente de dineína y donde el CE comienza a multiplicarse por fisión binaria. Las infecciones causadas por $C$. trachomatis pueden ocasionar daños graves tales como enfermedades pélvicas inflamatorias (EPI), infertilidad tubárica, embarazo ectópico, dolor abdominal en mujeres y en hombres prostatitis y epididimitis (Gotz et al., 2002).

La mayor parte de los estudios in vitro en hombres, buscan esclarecer el efecto que causa la bacteria en el espermatozoide, como se adhiere a él y como se propaga por el aparato reproductor femenino y masculino. Gran parte de los estudios en $C$. trachomatis utilizan microscopía electrónica o anticuerpos monoclonales para visualizar la adherencia del patógeno a los espermatozoides humanos, demostrado que $C$. trachomatis puede adherirse tanto a la superficie de la cabeza del espermatozoide como al flagelo o incluso se pueden encontrar en muestras de uretra y orina de primer chorro (Askienazy-Elbhar, 2005). Asimismo, el CE de C. trachomatis es capaz de penetrar la cabeza del espermatozoide, siendo éste, otro mecanismo de anclaje de la bacteria al espermatozoide. En hombres diagnosticados con prostatitis y $C$. trachomatis positiva, existe una asociación con la disminución de la fertilidad, considerando la baja concentración de espermatozoides, motilidad espermática, alta fragmentación de ADN, incremento de la reacción acrosómica. y morfología anormal en estos pacientes (Cunningham \& Beagley, 2008). Estudios in vitro de $C$. trachomatis en co-infección con espermatozoides humanos han evidenciado la prematura perdida de vitalidad de espermatozoides, esto como respuesta a los lipopolisacáridos presentes en $C$. trachomatis que resultan ser espermicida en comparación a otras formas de lipopolisacáridos (Eley et $a l ., 2005)$. También existen niveles elevados de interleucina 8 (IL-8), lo que hace sugerir a IL-8 como un potencial marcador para infecciones por $C$. trachomatis y una relación entre la infección por este microorganismo y las alteraciones en parámetros de la calidad del semen (Kokab et al., 2010).

Mollicutes (Ureaplasma y Mycoplasma). Otros de los microorganismos que se encuentran frecuentemente en el tracto genitourinario de pacientes sintomáticos y asintomáticos son los Mollicutes (Tibaldi et al., 2009). Estas bacterias carecen de pared celular, lo que les permite resistir tratamiento con antibióticos comunes, como la penicilina. Los Mollicutes que infectan el tracto genital son Mycoplasma genitalium, Mycoplasma hominis y Ureaplasma urealyticum.

Ureaplasma urealyticum posee la singular capacidad de hidrolizar la urea. Es potencialmente patógeno y tiene un rol etiológico infecciones del tracto urinario y genital (Gdoura et al., 2007). Se considera además el causal más reconocido de infertilidad en hombres al reducir la calidad del semen y el potencial de fertilización del espermatozoide (Sánchez et al., 1990, Fraczek \& Kurpisz, 2007). Mycoplasma genitalium es la bacteria de vida independiente más pequeña conocida, y la segunda bacteria más pequeña después de la recientemente descubierta Carsonella ruddii (Ross \& Jensen, 2006). Por otro lado, Mycoplasma hominis está asociada a la enfermedad inflamatoria pelviana y producir rotura prematura de membranas durante el embarazo. En la mujer la infección es más frecuente que en el hombre y al igual que la $C$. trachomatis, generalmente asintomática (Gdoura et al.). La incidencia de $U$. urealitycum, $M$. genitalium y M. hominis se asocia a trastornos como el aborto involuntario recurrente a infertilidad, enfermedad inflamatoria pélvica, orquitis, epididimitis, prostatitis, y prostatitis uretritis no gonocócica (Check, 2010; Haggerty \& Ness, 2008).

Los Mollicutes se encuentran frecuentemente en el tracto genital y semen de hombres fértiles e infértiles (Sánchez et al., 1990, Pellati et al.). En hombres fértiles de parejas infértiles existe una alta frecuencia de $U$. urealitycum, M. genitalium y $M$. hominis, que se ha asociado a una disminución en el recuento espermático (Gdoura et al.). Asimismo, hombres infectados por M. hominis presentan una reducción de la motilidad y concentración de espermatozoides, además de cambios en su morfología (Al Sweih et al., 2011), en cambio la infección de $U$. urealyticum o infecciones mixtas evidencian un aumento en la viscosidad y pH del fluido seminal (Zinzendorf et al., 2008). Estudios in vitro han permitido identificar el área del espermato- 
zoide a la cual se une $M$. hominis, siendo las zonas principales de unión la cabeza y la pieza media del espermatozoide, localizándose intracelularmente en los espacios citosólicos (Diaz-Garcia et al., 2006). M. genitalium puede unirse en la pieza intermedia o región del cuello de espermatozoides humanos tanto móviles como inmóviles, por lo que podría ser transportado hacia la pareja sexual causando enfermedades genitales y/o infertilidad (Svenstrup $e t$ al., 2003). Por otro lado, Wang et al. (2006) observaron que la infección con $U$. urealyticum aumentaba la viscosidad del semen y disminuía el pH en comparación con pacientes negativos.

$U$. urealyticum es capaz de competir con la producción de energía mitocondrial y por tanto, reduce la motilidad y viabilidad de espermatozoides. No obstante, cuando el metabolismo energético de los espermatozoides depende de la glucólisis, a valores de $\mathrm{pH}$ mayores, $U$. urealyticum estimula la glucólisis y la actividad de los espermatozoides, incrementando la tasa de penetración y fertilización de óvulos con esperma infectado, poniendo en peligro el desarrollo embrionario (Reichart et al., 2001).

Treponema pallidum. Es una bacteria perteneciente al grupo de las Spirochetaceae, cuya principal característica es su capacidad para moverse de manera eficiente en ambientes gelatinosos y/o viscosos donde la mayoría de las bacterias se retrasan o definitivamente se detienen (Liu et al., 2010). Es la causante de la sífilis, registrándose a lo menos 25 millones de personas en todo el mundo (WHO, 2001). Su vía más común de transmisión es a través de las membranas mucosas causando una lesión del tipo primaria conocida como chancro (Izard et al., 2009). La sífilis es un co-factor en la adquisición y transmisión del Virus de Inmunodeficiencia Humana, que marca cifras importantes en la causa de muerte fetal y morbilidad perinatal especialmente en países desarrollados (Schulz et al., 1987; Chesson et al., 1999).

Escherichia coli. Es un bacilo Gram negativo que pertenece al género Escherichia y es un miembro conocido de la familia Enterobacteriaceae (cavidad oral, esófago, estómago, intestinos, recto y ano (Manning et al., 2009). Es el microorganismo aislado con mayor frecuencia en pacientes con infecciones del tracto genital masculino (ITGM), además, se adhiere rápidamente a espermatozoides in vitro, resultando en una disminución de la movilidad y aglutinación de los mismos (Sánchez et al., 1989). Los espermatozoides infectados por E. coli son capaces de atravesar el mucus cervical y transportar la bacteria hasta el tracto genital femenino (Sánchez et al., 1989, Diemer et al., 2003). La presencia de E. coli en semen induce a una baja motilidad de espermatozoides dependiendo de la relación semen-bacte- ria que se encuentre presente. La unión de E. coli al espermatozoide es a través de residuos de azúcar, especialmente manosa, receptores que también son cruciales para la unión del espermatozoide a la zona pelúcida del ovocito (Sánchez et al., 1989, Auroux et al., 1991).

\section{VIRUS}

Virus Inmunodeficiencia Humana (HIV). El HIV pertenece a la familia Retroviridae y al género Lentivirus. Su material genético es RNA de cadena simple con una longitud de aproximadamente 9,5 kb (Girard et al., 2011). En el año 2010 se estima que 2,7 millones de personas fueron infectadas con este virus. Esta infección es transmitida por vía sexual donde el semen es el portador del virus (LeruezVille et al., 2005b). Existiendo factores del sistema reproductor masculino que ayudan a dicha infección, principalmente la co-infección con otros microorganismos de transmisión sexual (Zea-Mazo et al., 2010). Aunque la mayoría de las infecciones por HIV-1 resultan de la exposición del virus en el semen, no se ha establecido aún si las cepas transmisibles se originan como viriones de RNA en el plasma seminal o en forma de DNA proviral integrado en leucocitos seminales infectados (Butler et al., 2010). Las partículas virales, sus antígenos y el DNA se encuentran presentes en el semen de hombres infectados por HIV-1 y los espermatozoides pueden transferir partículas a ovocitos humanos normales (Baccetti et al., 1994). Los órganos del tracto genital masculino se encuentran infectados por HIV durante las fases aguda y crónica de la infección asintomática (Le Tortorec \& Dejucq-Rainsford, 2010). Existe evidencia molecular que sujetos infectados por HIV pueden eyacular pequeñas cantidades espermatozoides anormales HIV-1 DNA-positivos, sin embargo, espermatozoides HIV-1 DNApositivos que lleven una amplia variedad de alteraciones estructurales puede ser incapaz de fertilizar y/o generar embriones viables (Muciaccia et al., 2007). Es así, que los espermatozoides actúan concertadamente con células dendríticas (CDs) pudiendo afectar el curso temprano de la transmisión sexual de la infección por HIV-1, además de transmitirse de manera eficiente a macrófagos y células $\mathrm{T}$ (Ceballos et al., 2009). Finalmente, teniendo en consideración que el semen es la principal vía de transmisión del HIV1 , es poco lo que se conoce acerca de sus efectos sobre la inefectividad viral (Munch et al., 2007). Aún existe contradicción a cerca de los parámetros espermáticos y cómo éstos se ven afectados por la presencia del HIV-1, siendo en algunos estudios afectados de forma completa por la presencia del virus y en otros ensayos de forma irregular (Nicopoullos et al., 2004).

Virus Papiloma Humano (HPV). El HPV es un virus de DNA pequeño, sin envoltura, perteneciente a la familia de 
los Papillomaviridae. Es una de las ITS más frecuentes en el mundo y es descrito como el principal agente causal del cáncer cervicouterino (99,7\%) (Clifford et al., 2003). El HPV afecta a hombres y mujeres por igual, sin embargo, en hombres sólo se ha asociado a lesiones como verrugas anogenitales y aún es discutida su participación en neoplasias intraepiteliales de pene y ano (Petersen \& Klein, 2008). El HPV puede encontrarse en el semen de hombres sexualmente activos, asociado a la posible infertilidad masculina debido al deterioro de los parámetros espermáticos, especialmente la motilidad (Garolla et al., 2012). La infección por HPV en semen se asocia a espermatozoides y plasma seminal siendo su mecanismo de unión aún desconocido, sin embargo, se cree que este estaría mediado por heparán sulfato que interactúa con la cápside viral (Zea-Mazo et al., 2010). El HPV se une al espermatozoide utilizando su cápside viral y esta se realiza en dos sitios, la región ecuatorial y la superficie de la cabeza. Además, la unión del virus con el espermatozoide puede estar condicionado pordos inhibidores de la infección, la heparina y carragenina (Perez-Andino et al., 2009). Estudios con hibridación in situ se identificó que los genomas de HPV 6, 16, 18 y 31 se asociaban cerca de la cabeza de espermatozoides o al segmento ecuatorial, evidenciando que la mayoría de los tipos de alto riesgo se unen al segmento ecuatorial de la célula espermática (Kaspersen et al., 2011). Asimismo, el HPV puede infectar espermatozoides humanos a través de la interacción entre la proteína L1de la cápside del HPV y syndecan-1. Existiendo espermatozoides transfectados con genes E6/E7 de HPV y proteínas L1 expuestas de la cápside, que son capaces de penetrar en el ovocito y transferir el virus en donde finalmente se transcribe (Foresta et al., 2011). Aún queda mucho por investigar a cerca del lugar preciso y el mecanismo de unión de HPV a espermatozoides, así como los lugares de reservorios que ocupa este patógeno en hombres.

Virus Herpes Simplex (HSV). HSV pertenece a una gran familia de virus de gran envoltura conocida como Herpesviridae, la cual se divide en tres subfamilias (a, b, g). Específicamente el HSV pertenece a la subfamilia Alphaherpesvirinae. Su genoma se compone de DNA bicatenario (125-250 kb aproximadamente) presente dentro de una cápside icosaédrica. Dentro de los HSV los más comunes y asociados a ITS se encuentran los HSV tipo 1 y 2. HSV-1 es el causante del herpes labial en tanto, las infecciones por HSV-2 se encuentra relacionadas con infecciones virales del tracto genitourinario e infecta a la mayoría de los órganos del sistema reproductor masculino a excepción de los tubos seminíferos, debido a la protección que presentan por la barrera hemato-testicular. Sin embargo, el semen igualmente puede ser contaminado a medida que pasa durante la eyaculación. HSV-1 y HSV-2 pueden infectar diversas porciones del eyaculado como son los espermatozoides, el plasma seminal, células epiteliales o glándulas accesorias y leucocitos aunque aún no se ha establecido el mecanismo concreto por el cual ocurre la infección (Zea-Mazo et al.). La infección por estos virus en el tracto genital masculino pudiesen explicar los casos de infertilidad masculina debido a la asociación de la presencia de HSV en semen con la disminución de la calidad del mismo (Pellati et al.). Estudios realizados en glándulas anexas, concluyen que al mezclar el virus HSV-2 con semen, HSV2 no interactúa con el espermatozoide, permaneciendo en el fluido seminal, lo que podría ser un factor a favor para las técnicas de reproducción asistida, en las cuales, al eliminar el fluido seminal estarían eliminando partículas virales y mejorando con ellos las preparaciones de espermatozoides (Pallier et al., 2002). HSV-2 ha sido detectado en la próstata y conductos deferentes, y de manera más general, en el tracto genital masculino (Courtot et al., 2004), existiendo además DNA viral de HSV1 y HSV2 a nivel de núcleos en espermatozoides (Kotronias \& Kapranos, 1998).

Citomegalovirus (CMV). Citomegalovirus humano (HCMV) es un virus perteneciente a la familia Herpesviridae, a la cual también pertenecen HSV 1- 2 y el virus Epstein-Barr (Chen et al., 1996), aunque HCMV pertenece a la subfamilia Betaherpesvirinae. Su genoma presenta un DNA de doble cadena, lineal, rodeado por una capa proteica que a su vez se encuentra protegida por una bicapa lipidica conteniendo un gran número de glicoproteínas virales. Se comporta como infección oportunista en pacientes portadores de HIV (alrededor del 90\% de los pacientes) y como infección latente en más del 50\% de la población general (Li et al., 2012). Las diversas vías de transmisión de HCMV pueden ser la saliva, la actividad sexual, la transferencia placentaria, la lactancia materna, transfusiones de sangre y órganos sólidos o trasplantes de células madre hematopoyéticas (Mercorelli et al., 2011). HCMV es capaz de infectar tanto a células espermáticas como a los leucocitos presentes en el eyaculado cuyo mecanismo de infección, al igual que HSV, aun es desconocido (Zea-Mazo et al.). CMV se encuentra presente en el semen, ya sea de forma continua por un prolongado periodo de tiempo, un periodo puntual o bien, de forma intermitente (Courtot et al.). CMV se encuentra presente tanto en secreciones genitales como en glándulas salivales, aunque aún no se determina la vía preferida para la contaminación. Sin embargo, frecuentemente la cepa de CMV se encuentra en el moco cervical de mujeres con CMV lo que hace posible la transmisión del virus a través del contacto sexual (Liesnard et al., 2001). En las infecciones comunitarias, el virus se transmite ya sea por contacto con saliva o por secreciones del tracto genital donde las principales células infectadas por CMV son las células endoteliales y leucocitos (Benoist et al., 2008). En el año 2001, la Sociedad Británica de Andrología recomendó ex- 
cluir a todos los donantes de semen CMV positivos con el fin de prevenir el riesgo de infección congénita por CMV, ésto debido a resultados de estudios que identificaron un alto porcentaje de infecciones sintomáticas congénitas por CMV en recién nacidos de mujeres con seropositividad CMV preexistente con el embarazo y en el hecho de que el CMV puede ser detectado en el semen de los hombres CMV seropositivos (Liesnard et al.). Actualmente, aun existe controversia y debate sobre el riesgo relacionado con el CMV en la reproducción y en qué medida el semen se ve implicado (Bresson et al., 2003).

Virus Epstein-Barr (EBV). El virus de Epstein-Barr (EBV) o Herpesvirus Humano 4 pertenece a la familia de los herpesvirus y se considera dentro de los virus linfoproliferativos. La mononucleosis es la principal infección causada por EBV, la cual se desarrolla en la adolescencia y en edad adulta (Tarbouriech et al., 2006). Su genoma se representa como una molécula lineal de DNA bicatenario (172kb), con repeticiones reiteradas terminales de $0,5 \mathrm{~kb}$ y repeticiones reiteradas internas directa de $3 \mathrm{~kb}$ (Middeldorp et al., 2003). El EBV ha sido detectado en secreciones genitales masculinas y femeninas, sugiriendo como vía de transmisión, además de la saliva y transfusiones sanguíneas, la vía sexual (Levine et al., 2012). Su replicación puede ocurrir en el epitelio del cérvix uterino lo cual refuerza esta teoría (Turner et al., 1990). El plasma seminal facilita la replicación de EBV en el cuello uterino (Dejucq-Rainsford \& Jegou, 2001), lo cual fue corroborado en ensayos in vitro donde el semen humano poseía la capacidad de inducir la replicación de EBV (Ida et al., 1991). Aún existe poca información acerca de EBV en semen, por lo que son necesarios nuevos ensayos que permitan dilucidar esta incógnita.

Virus de la hepatitis B y C. Existen diversos tipos de virus que causan la hepatitis, enfermedad que tiene como órgano blanco al hígado y causa ictericia y secreción de enzimas hepáticas. Los agentes virales causantes de la hepatitis descritos hasta el momento son: Virus de la Hepatitis A, B, C, D, E y G. A continuación se describirán los Virus de la Hepatitis B (HBV) y Virus de la Hepatitis C (HCV), debido a que estos dos tipos virus se han encontrado presentes en el semen y probablemente sean transmitidos por esta vía a la pareja sexual.

Virus de la hepatitis B. El Virus de la Hepatitis B (HBV) pertenece a la familia Hepadnaviridae. Tiene un genoma de DNA de doble hebra el cual se transcribe de forma inversa a partir de un RNA pre-genómico dentro del núcleo del virus (o de la cápside) (Wang et al., 2012; Zea-Mazo et al.). Las infecciones por HBV es la principal causa de las enfermedades como cirrosis y cáncer hepatocelular, infectando alrededor de 70 millones de personas a nivel mundial. El HBV se ha encontrado en sangre, saliva, leche materna, secreciones vaginales y semen, siendo transmitido principalmente por vía parenteral, sexual y perinatal (Zea-Mazo et al.). Se ha determinado secuencias de DNA de HBV en cromosomas de espermatozoides, donde el virus posiblemente ha atravesado la barrera hematotesticular e infectado a la línea germinal masculina y también en oocitos de ratón, lo cual es de gran importancia debido a la posibilidad que el feto pueda adquirir la infección a través de la madre (Huang et al., 2005). En humanos, el virus es detectable en muestras de semen de hombres con hepatitis B aguda así como en el semen de hombres con hepatitis crónica (Leruez-Ville et al., 2005a).

Virus de la hepatitis C. El Virus de la Hepatitis C (HCV) pertenece a la familia Flaviviridae, al género Hepacivirus y es el principal agente causal de la hepatitis crónica. Posee un genoma RNA lineal de aproximadamente 10.000 nucleótidos (Chandler et al., 2012). Generalmente es transmitida por el uso de drogas y transfusiones de sangre, aunque también se puede dar por contacto sexual y transmisión vertical.

La posibilidad de que HCV pueda infectar al semen es controversial. Algunos estudios encuentran DNA del virus en semen, mientras que otros no (Levy et al., 2002). Se postula que el virus no posee la capacidad de integrar su genoma en las células seminales, debido a que no es un virus DNA, como si lo es el HBV y no posee actividad de transcriptasa reversa, como es el caso del HIV. También, hay que consideras que la concentración viral en el plasma seminal varía rápidamente con el tiempo (Zea-Mazo et al.). Ante esta situación es posible que HCV se encuentre en una baja carga y cuya detección dependa de la metodología empleada.

\section{PROTOZOOS}

Trichomonas vaginalis. T. vaginalis es un protozoo aerotolerante flagelado que infecta a las células extracelularmente. A su vez es la infección de transmisión no viral más prevalente en el mundo, causante de la enfermedad conocida como Tricomoniasis (WHO) y que anualmente el número de infectados va de 160 a 180 millones de personas en todo el mundo (McClelland, 2008). La infección por este protozoo causa diversas consecuencias para la salud de la mujeres tales como infertilidad, parto prematuro, recién nacidos con bajo peso al nacer y predisposición a la neoplasia cervical, entre otras (Cotch et al., 1997; ElShazly et al., 2001; Viikki et al., 2000). En el hombre la infección puede estar asociada a uretritis, prostatitis y que puede aumenta la probabilidad de transmisión del virus de HIV, sin embargo, en la mayoría de los casos es asintomática, por lo que se reporta una baja incidencia de esta infección en hombres (Kaydos-Daniels et al., 2003). 
Estudios de propagación de T. vaginalis señalan que los espermatozoides de hombres infectados pueden ser una vía de transmisión de la enfermedad, existiendo una estrecha proximidad y finalmente una fuerte adhesión entre la $T$. vaginalis y espermatozoides. Esta adhesión se observó en la cabeza y en el flagelo (Benchimol et al., 2008). La presencia de T. vaginalis en semen no altera la motilidad de los espermatozoides ni tampoco el semen inhibe la supervivencia de T. vaginalis. Estos datos sugieren que el semen proporcionaría un entorno favorable para la transmisión de tricomonas por la vía sexual (Daly et al., 1989).

En la figura 1 se resumen la localización en el semen y/o espermatozoide de cada uno de estos microorganismos .

\section{COMENTARIOS FINALES Y DIRECCIONES FUTU- RAS}

Las ITS han sido históricamente un problema difícil de resolver. Además de provocar lesiones en el sitio de contagio, muchas de ellas tienen manifestaciones sistémicas importantes que hacen necesario que el médico tratante esté en conocimiento de su semiología, tratamiento y complicacio- nes. Por otro lado, gran parte de las ITS son asintomáticas lo cual provoca que un gran número de portadores continúen la cadena de transmisión sin saberlo.

Las ITS comparten como vía de transmisión el contacto sexual. Es por ello que en los últimos años el estudio de las ITS asociadas a semen ha cobrado gran importancia. Existe un gran número de ITS que se propagan por la vía seminal, ya sea por la adhesión del patógeno al espermatozoide, por su inclusión en la cola y/o cabeza, o por sus capacidades de infectar a las diversas fracciones del fluido seminal (espermatozoides, plasma seminal, leucocitos, entre otros). Si bien existen estudios sobre la asociación patógeno-espermatozoide muchos de ellos no son concluyentes debido a que la detección de esta unión es compleja y en algunos casos, poco clara.

Actualmente existe un creciente interés científico por conocer el mecanismo de transmisión de este tipo de infecciones, debido a que el plasma seminal incluido sus células y los espermatozoides se constituyen en los principales vectores de la transmisión de un gran número de ITS, lo cual sugiere que las campañas de prevención deberían incluir el diagnostico precoz de estas infecciones en el varón.

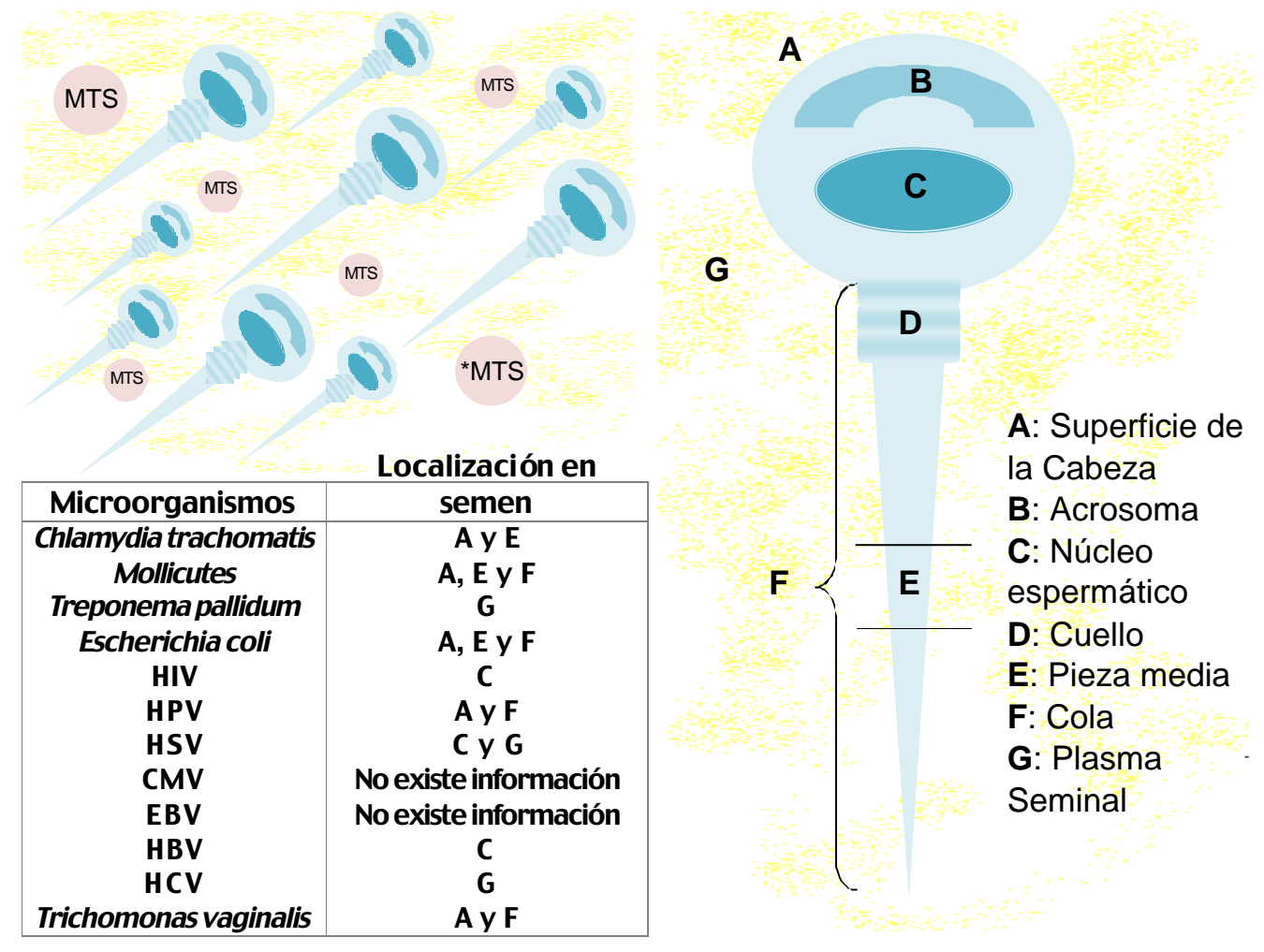

Fig. 1. Localización de microorganismos (Chlamydia trachomatis, Mollicutes, Treponema pallidum, Escherichia coli, Virus Inmunodeficiencia Humana [HIV], Virus Papiloma Humano [HPV], Virus Herpes Simplex [HSV], Citomegalovirus [CMV], Virus Epstein-Barr [EBV], Virus de la hepatitis B y C y Trichomonas vaginalis) en semen. * MTS: Microorganismo de transmisión sexual. 
VISCARRA, A. T.; BREBI, M. P.; ANDANA, V. A. \& SÁNCHEZ, G. R. Sexual transmission infections in semen. Men as vector transmission. Int. J. Morphol., 31(1):254-263, 2013.

SUMMARY: Sexually transmitted infections study has become an important issue in these days, mainly due to the increment of heterosexual and men have sex with men partners of people. In women, there is a lot information about epidemiology and pathogenesis of these infections. However, the information is very limited in men, because most infected men are asymptomatic. In recent years, there has been an increasing interest in study of semen as a transmission way, due to the affinity of some pathogens to sperm. The most prevalent microorganisms infecting semen are: Chlamydia trachomatis, Neisseria gonorrhoeae, Mollicutes, Human Immunodeficiency Virus Types 1 and 2 Herpes Simplex Virus 1 and 2, Human Papillomavirus, Hepatitis B and C virus, Cytomegalovirus, Epstein-Barr and Trichomonas vaginalis.

KEY WORDS: Sexually transmitted infections; Semen; Viruses; Bacteria, Protozoa.

\section{REFERENCIAS BIBLIOGRÁFICAS}

Al Sweih, N. A.; Al Fadli, A. H.; Omu, A. E. \& Rotimi, V. O. Prevalence of Chlamydia trachomatis, Mycoplasma hominis, Mycoplasma genitalium and Ureaplasma urealyticum Infections and Seminal Quality in Infertile and Fertile Men in Kuwait. J. Androl., 33(6):1323-9, 2012.

Apers, L.; Crucitti, T.; Verbrugge, R., \& Vandenbruaene, M. Sexually transmitted infections: what's new? Acta Clin. Belg., 67:154-9, 2012.

Askienazy-Elbhar, M. Male genital tract infection: the point of view of the bacteriologist. Gynecol. Obstet. Fertil.,33:691-7, 2005.

Auroux, M. R.; Jacques, L.; Mathieu, D. \& Auer, J. Is the sperm bacterial ratio a determining factor in impairment of sperm motility: an in-vitro study in man with Escherichia coli. Int. J. Androl., 14:264-70, 1991.

Baccetti, B.; Benedetto, A.; Burrini, A. G.; Collodel, G., Ceccarini, E. C.; Crisa, N.; Di Caro, A.; Estenoz, M.; Garbuglia, A. R.; Massacesi, A. et al. HIV-particles in spermatozoa of patients with AIDS and their transfer into the oocyte. J. Cell Biol., 127:903-14, 1994.

Benchimol, M.; de Andrade Rosa, I.; da Silva Fontes, R. \& Burla Dias, A. J. Trichomonas adhere and phagocytose sperm cells: adhesion seems to be a prominent stage during interaction. Parasitol. Res., 102:597-604, 2008.

Benoist, G.; Jacquemard, F.; Leruez-Ville, M. \& Ville, Y. Infection congénitale à Cytomégalovirus (CMV). Gynécologie Obstétrique \& Fertilité, 36:248-60, 2008.

Bresson, J. L.; Clavequin, M. C.; Mazeron, M. C.; Mengelle, C.; Scieux, C.; Segondy, M. \& Houhou, N. Risk of cytomegalovirus transmission by cryopreserved semen: a study of 635 semen samples from 231 donors. Hum. Reprod., 18:1881-6, 2003.

Butler, D. M.; Delport, W.; Kosakovsky Pond, S. L.; Lakdawala, M. K.; Cheng, P. M.; Little, S. J.; Richman, D. D. \& Smith, D.
M. The origins of sexually transmitted HIV among men who have sex with men. Sci. Transl. Med., 2(18):18re11, 2010.

Ceballos, A.; Remes Lenicov, F.; Sabatte, J.; Rodriguez Rodrigues, C.; Cabrini, M.; Jancic, C.; Raiden, S.; Donaldson, M.; Agustin Pasqualini, R.; Jr., Marin-Briggiler, C. et al. Spermatozoa capture HIV-1 through heparan sulfate and efficiently transmit the virus to dendritic cells. J. Exp. Med., 206:2717-33, 2009.

Chesson, H. W.; Pinkerton, S. D.; Irwin, K. L., Rein, D. \& Kassler, W. J. New HIV cases attributable to syphilis in the USA: estimates from a simplified transmission model. AIDS, 13:1387-96, 1999.

Clifford, G. M.; Smith, J. S.; Plummer, M.; Munoz, N. \& Franceschi, S. Human papillomavirus types in invasive cervical cancer worldwide: a meta-analysis. Br. J. Cancer, 88:6373, 2003.

Cotch, M. F., Pastorek, J. G., 2nd, Nugent, R. P., Hillier, S. L., Gibbs, R. S., Martin, D. H., Eschenbach, D. A., Edelman, R., Carey, J. C., Regan, J. A. et al. Trichomonas vaginalis associated with low birth weight and preterm delivery. The Vaginal Infections and Prematurity Study Group. Sex. Transm. Dis., 24:353-60, 1997.

Courtot, A. M.; Pallier, C. \& Testart, J. Viral transmission and medically assisted procreation: the Herpesviridae case. Gynecol. Obstet. Fertil,, 32:233-40, 2004.

Cunningham, K. A. \& Beagley, K. W. Male genital tract chlamydial infection: implications for pathology and infertility. Biol. Reprod., 79:180-9, 2008.

Chandler, D. E.; Penin, F.; Schulten, K. \& Chipot, C. The p7 Protein of Hepatitis C Virus Forms Structurally Plastic, Minimalist Ion Channels. PLoS Comput. Biol., 8:e1002702, 2012.

Check, J. H. A practical approach to the prevention of miscarriage. Part 4--role of infection. Clin. Exp. Obstet. Gynecol., 37:2525,2010 . 
Chen, P.; Tsuge, H.; Almassy, R. J.; Gribskov, C. L.; Katoh, S.; Vanderpool, D. L.; Margosiak, S. A.; Pinko, C.; Matthews, D. A. \& Kan, C. C. Structure of the human cytomegalovirus protease catalytic domain reveals a novel serine protease fold and catalytic triad. Cell, 86:835-43, 1996.

Daly, J. J.; Sherman, J. K.; Green, L. \& Hostetler, T. L. Survival of Trichomonas vaginalis in human semen. Genitourin. Med., 65:106-8, 1989.

Dejucq- Rainsford, N. \& Jegou, B. Viruses in the mammalian male genital tract and their effects on the reproductive system. Microbiol. Mol. Biol. Rev., 65:208-31, 2001.

Dejucq-Rainsford, N. \& Jegou, B. Viruses in semen and male genital tissues--consequences for the reproductive system and therapeutic perspectives. Curr. Pharm. Des., 10:557-75, 2004.

Diaz-Garcia, F. J.; Herrera-Mendoza, A. P.; Giono-Cerezo, S. \& Guerra-Infante, F. M. Mycoplasma hominis attaches to and locates intracellularly in human spermatozoa. Hum. Reprod., 21:15918, 2006.

Diemer, T.; Huwe, P.; Ludwig, M.; Schroeder-Printzen, I.; Michelmann, H. W.; Schiefer, H. G. \& Weidner, W. Influence of autogenous leucocytes and Escherichia coli on sperm motility parameters in vitro. Andrologia, 35:100-5, 2003.

El-Shazly, A. M.; El-Naggar, H. M.; Soliman, M.; El-Negeri, M.; ElNemr, H. E.; Handousa, A. E. \& Morsy, T. A. A study on Trichomoniasis vaginalis and female infertility. J. Egypt Soc. Parasitol., 31:545-53, 2001.

Eley, A.; Pacey, A. A.; Galdiero, M. \& Galdiero, F. Can Chlamydia trachomatis directly damage your sperm? Lancet Infect. Dis., 5:53-7, 2005

Foresta, C.; Patassini, C.; Bertoldo, A.; Menegazzo, M.; Francavilla, F.; Barzon, L. \& Ferlin, A. Mechanism of human papillomavirus binding to human spermatozoa and fertilizing ability of infected spermatozoa. PLoS One 6:e15036, 2011.

Fraczek, M. \& Kurpisz, M. Inflammatory mediators exert toxic effects of oxidative stress on human spermatozoa. J. Androl., 28:32533, 2007.

Garolla, A.; Lenzi, A.; Palu, G.; Pizzol, D.; Bertoldo, A.; De Toni, L. $\&$ Foresta, C. Human papillomavirus sperm infection and assisted reproduction: a dangerous hazard with a possible safe solution. Hum. Reprod., 27:967-73, 2012.

Gdoura, R.; Kchaou, W.; Chaari, C.; Znazen, A.; Keskes, L., Rebai, T. \& Hammami, A. Ureaplasma urealyticum, Ureaplasma parvum, Mycoplasma hominis and Mycoplasma genitalium infections and semen quality of infertile men. BMC Infect. Dis., 7:129, 2007.

Girard, M. P.; Osmanov, S.; Assossou, O. M. \& Kieny, M. P. Human immunodeficiency virus (HIV) immunopathogenesis and vaccine development: a review. Vaccine, 29:6191-218, 2011.
Giuliano, A. R.; Lazcano-Ponce, E.; Villa, L. L.; Flores, R.; Salmeron, J.; Lee, J. H.; Papenfuss, M. R.; Abrahamsen, M.; Jolles, E.; Nielson, C. M.; et al. The human papillomavirus infection in men study: human papillomavirus prevalence and type distribution among men residing in Brazil, Mexico, and the United States. Cancer Epidemiol. Biomarkers Prev. 17:2036-43, 2008.

Gotz, H.; Lindback, J.; Ripa, T.; Arneborn, M.; Ramsted, K. \& Ekdahl, K. Is the increase in notifications of Chlamydia trachomatis infections in Sweden the result of changes in prevalence, sampling frequency or diagnostic methods? Scand. J. Infect. Dis., 34:28-34, 2002.

Gupta, N. K. \& Bowman, C. A. Managing sexually transmitted infections in pregnant women. Womens Health, 8:313-21, 2012.

Haggerty, C. L. \& Ness, R. B. Diagnosis and treatment of pelvic inflammatory disease. Womens Health, 4,:383-97, 2008.

Huang, T. H.; Zhang, Q. J.; Xie, Q. D.; Zeng, L. P. \& Zeng, X. F. Presence and integration of HBV DNA in mouse oocytes. World J. Gastroenterol., 11:2869-73, 2005.

Ida, K.; Tokuda, H.; Kanaoka, T.; Kanzaki, H.; Noda, Y.; Yoshida, O.; Ito, Y.; \& Mori, T. Epstein-Barr virus activating principle in husbands' semen of cervical cancer patients. Am. J. Reprod. Immunol., 26:89-92, 1991.

Izard, J.; Renken, C.; Hsieh, C. E.; Desrosiers, D. C.; Dunham-Ems, S.; La Vake, C.; Gebhardt, L. L.; Limberger, R. J.; Cox, D. L.; Marko, M. \& Radolf, J. D. Cryo-electron tomography elucidates the molecular architecture of Treponema pallidum, the syphilis spirochete. J. Bacteriol., 191:7566-80, 2009.

Kaspersen, M. D.; Larsen, P. B.; Ingerslev, H. J.; Fedder, J.; Petersen, G. B.; Bonde, J. \& Hollsberg, P. Identification of multiple HPV types on spermatozoa from human sperm donors. PLoS One, 6: e18095, 2011.

Kaydos-Daniels, S. C.; Miller, W. C.; Hoffman, I.; Banda, T.; Dzinyemba, W.; Martinson, F.; Cohen, M. S. \& Hobbs, M. M. Validation of a urine-based PCR-enzyme-linked immunosorbent assay for use in clinical research settings to detect Trichomonas vaginalis in men. J. Clin. Microbiol., 41:318-23, 2003.

Kokab, A., Akhondi, M. M.; Sadeghi, M. R.; Modarresi, M. H.; Aarabi, M.; Jennings, R.; Pacey, A. A. \& Eley, A. Raised inflammatory markers in semen from men with asymptomatic chlamydial infection. J. Androl., 31:114-20, 2010.

Kotronias, D. \& Kapranos, N. Detection of herpes simplex virus DNA in human spermatozoa by in situ hybridization technique. In Vivo, 12:391-4, 1998.

Le Tortorec, A. \& Dejucq-Rainsford, N. HIV infection of the male genital tract--consequences for sexual transmission and reproduction. Int. J. Androl., 33: e98-108, 2010. 
Leruez-Ville, M.; Galimand, J.; Ghosn, J.; Briat, A.; Delaugerre, C. \& Chaix, M. L. Infection du tractus génital masculin : le point de vue du virologue. Gynécologie Obstétrique \& Fertilité 33:684-90, 2005a.

Leruez-Ville, M.; Galimand, J.; Ghosn, J., Briat, A.; Delaugerre, C. \& Chaix, M. L. Male genital tract infection: the point of view of the virologist. Gynecol. Obstet. Fertil., 33:684-90, $2005 b$

Levine, H.; Balicer, R. D., Rozhavski, V.; Halperin, T.; Shreberk, M.; Davidovitch, N.; Huerta-Hartal, M. \& Ankol, O. E. Seroepidemiology of Epstein-Barr virus and cytomegalovirus among Israeli male young adults. Ann. Epidemiol., 22(11):783-8, 2012.

Levy, R.; Bourlet, T.; Maertens, A.; Salle, B.; Lornage, J.; Laurent, J. L.; Pozzetto, B. \& Guerin, J. F. Pregnancy after safe IVF with hepatitis C virus RNA-positive sperm. Hum. Reprod., 17:2650-3, 2002.

Li, C.; Samaranayake, N. R.; Ong, K. L.; Wong, H. K. \& Cheung, B. M. Is human cytomegalovirus infection associated with hypertension? The United States National Health and Nutrition Examination Survey 1999-2002. PLoS One 7, e39760, 2012.

Liesnard, C.; Strebelle, E. \& Englert, Y. Screening standards in assisted reproductive technologies. Is the British Andrology Society recommendation to recruit cytomegalovirus negative semen donors only, a reasonable one? Hum. Reprod., 16:178991, 2001.

Liu, J.; Howell, J. K.; Bradley, S. D.; Zheng, Y.; Zhou, Z. H. \& Norris, S. J. Cellular architecture of Treponema pallidum: novel flagellum, periplasmic cone, and cell envelope as revealed by cryo electron tomography. J. Mol. Biol., 403:546$61,2010$.

Manning, S. D. Escherichia Coli Infections: Facts On File, Incorporated. 2nd Ed.2, Infobase Publishing, 2009.

McClelland, R. S. Trichomonas vaginalis infection: can we afford to do nothing? J. Infect. Dis., 197:487-9, 2008.

Mercorelli, B.; Lembo, D.; Palu, G. \& Loregian, A. Early inhibitors of human cytomegalovirus: state-of-art and therapeutic perspectives. Pharmacol. Ther., 131:309-29, 2011.

Middeldorp, J. M., Brink, A. A., van den Brule, A. J., \& Meijer, C. J. Pathogenic roles for Epstein-Barr virus (EBV) gene products in EBV-associated proliferative disorders. Crit. Rev. Oncol. Hematol., 45:1-36, 2003.

Muciaccia, B.; Corallini, S., Vicini, E., Padula, F., Gandini, L.; Liuzzi, G.; Lenzi, A. \& Stefanini, M. HIV-1 viral DNA is present in ejaculated abnormal spermatozoa of seropositive subjects. Hum. Reprod., 22:2868-78, 2007.
Munch, J.; Rucker, E.; Standker, L.; Adermann, K.; Goffinet, C.; Schindler, M.; Wildum, S.; Chinnadurai, R.; Rajan, D.; Specht, A., et al. Semen-derived amyloid fibrils drastically enhance HIV infection. Cell, 131:1059-71, 2007.

Nicopoullos, J. D.; Almeida, P. A.; Ramsay, J. W. \& Gilling-Smith, C. (2004). The effect of human immunodeficiency virus on sperm parameters and the outcome of intrauterine insemination following sperm washing. Hum. Reprod., 19:2289-97, 2004.

Pallier, C.; Tebourbi, L.; Chopineau-Proust, S.; Schoevaert, D.; Nordmann, P.; Testart, J. \& Courtot, A. M. Herpesvirus, cytomegalovirus, human sperm and assisted fertilization. Hum. Reprod., 17:1281-7, 2002.

Pellati, D.; Mylonakis, I.; Bertoloni, G.; Fiore, C.; Andrisani, A.; Ambrosini, G. \& Armanini, D. Genital tract infections and infertility. Eur. J. Obstet. Gynecol. Reprod. Biol., 140:3-11, 2008.

Perez-Andino, J.; Buck, C. B. \& Ribbeck, K. Adsorption of human papillomavirus 16 to live human sperm. PLoS One 4, e5847, 2009.

Petersen, I. \& Klein, F. HPV in non-gynecological tumors. Pathologe, 29 Suppl 2:118-22, 2008.

Reichart, M.; Levi, H.; Kahane, I. \& Bartoov, B. Dual energy metabolism-dependent effect of Ureaplasma urealyticum infection on sperm activity. J. Androl., 22:404-12, 2001.

Ross, J. D. \& Jensen, J. S. Mycoplasma genitalium as a sexually transmitted infection: implications for screening, testing, and treatment. Sex Transm. Infect., 82:269-71, 2006.

Sánchez R.; Villagrán, E.; Concha, M.; Cornejo, R. Ultrastructural analysis of the attachment sites of Escherichia coli to the human spermatozoon after in vitro migration through estrogenic cervical mucus. Int J. Fertil., 34:363-7, 1989.

Sánchez R.; Hein R.; Concha M.; Vigil P. \& Schill W.-B. Mollicutes in Male Infertility: Is Antibiotic Therapy Indicated? Andrologia, 22:355-60, 1990.

Shim, B. S. Current concepts in bacterial sexually transmitted diseases. Korean J. Urol., 52:589-97, 2011.

Schulz, K.F.; Cates, W. Jr. \& O'Mara, P. R. Pregnancy loss, infant death, and suffering: legacy of syphilis and gonorrhoea in Africa. Genitourin. Med., 63320-5, 1987.

Svenstrup, H. F.; Fedder, J.; Abraham-Peskir, J.; Birkelund, S. \& Christiansen, G. Mycoplasma genitalium attaches to human spermatozoa. Hum. Reprod., 18:2103-9, 2003.

Tarbouriech, N.; Ruggiero, F.; de Turenne-Tessier, M.; Ooka, T. $\&$ Burmeister, W. P. Structure of the Epstein-Barr virus oncogene BARF1. J. Mol. Biol., 359:667-78, 2006. 
Tibaldi, C.; Cappello, N.; Latino, M. A.; Masuelli, G.; Marini, S. \& Benedetto, C. Vaginal and endocervical microorganisms in symptomatic and asymptomatic non-pregnant females: risk factors and rates of occurrence. Clin. Microbiol. Infect., 15:6709, 2009.

Turner, M. J.; White, J. O. \& Soutter, W. P. Human seminal plasma inhibits the lymphocyte response to infection with EpsteinBarr virus. Gynecol. Oncol., 37:60-5, 1990.

Viikki, M.; Pukkala, E.; Nieminen, P. \& Hakama, M. Gynaecological infections as risk determinants of subsequent cervical neoplasia. Acta Oncol., 39:71-5, 2000.

Wang, J. C.; Dhason, M. S. \& Zlotnick, A. (2012). Structural organization of pregenomic RNA and the carboxy-terminal domain of the capsid protein of hepatitis B virus. PLoS Pathog 8, e1002919, 2012.

Wang, Y., Liang, C. L., Wu, J. Q., Xu, C., Qin, S. X. \& Gao, E. S. Do Ureaplasma urealyticum infections in the genital tract affect semen quality? Asian J. Androl., 8:562-8, 2006.

World Health Organization. (WHO). Dept. of Epidemic and Pandemic Alert and Response. Global prevalence and incidence of selected curable sexually transmitted infections: overview and estimates, Geneva WHO, 2001.

Zea-Mazo, J. W.; Negrette-Mejia, Y. A. \& Cardona-Maya, W. Virus of sexual transmission: semen and virus relationship. Actas Urol. Esp., 34:845-53, 2010.

Zinzendorf, N.Y.; Kouassi-Agbessi, B. T.; Lathro, J. S., Don, C. \& Kouadio, L. Ureaplasma Urealyticum or Mycoplasma Hominis Infections and Semen Quality of Infertile Men in Abidjan. $J$. Reprod. Contracep., 19:65-72, 2008.

\author{
Dirección para correspondencia: \\ Dr. Raúl Sánchez Gutiérrez, \\ Laboratorio de Virus Oncológicos en Reproducción, \\ Centro de Estudios Genéticos e Inmunológicos (CEGIN), \\ Facultad de Medicina \\ Universidad de La Frontera, \\ Manuel Montt 112, Temuco, \\ CHILE. \\ Tel.: +56 45744248 ; \\ Fax: +56 45325600 \\ Email: rsanchez@ufro.cl
}

Recibido : 27-11-2012

Aceptado: 16-12-2012 